\title{
Complexation of quaternary ammonium ions by tetraester derivatives of [3.1.3.1]homooxacalixarene in mobile and in fixed conformation
}

\author{
Bernardo Masci, Daniela Persiani, Pierre Thuéry
}

Dipartimento di Chimica and IMC-CNR, Università La Sapienza, P.le Aldo Moro 5, 00185 Roma, Italy, and CEA/Saclay, SCM (CNRS URA 331), Bât. 125, 91191 Gif-sur-Yvette, France.

\section{Supporting Information}

S2 General methods

S3 Synthesis of compounds $5,6,7 \mathbf{p}$ and $8 \mathbf{c}$.

S4 $\quad{ }^{1} \mathrm{H}$ and ${ }^{13} \mathrm{C}$ NMR spectra of compound 5 in $\mathrm{CDCl}_{3}$ at $298 \mathrm{~K}$.

S5 $\quad{ }^{1} \mathrm{H}$ and ${ }^{13} \mathrm{C}$ NMR spectra of compound 6 in $\mathrm{CDCl}_{3}$ at $298 \mathrm{~K}$.

S6 $\quad{ }^{1} \mathrm{H}$ and ${ }^{13} \mathrm{C}$ NMR spectra of compound $7 \mathbf{c}$ in $\mathrm{CDCl}_{3}$ at $298 \mathrm{~K}$.

S7-S8 $\quad{ }^{1} \mathrm{H}$ and ${ }^{13} \mathrm{C}$ NMR spectra of compound $\mathbf{7 p}$ in $\mathrm{CDCl}_{3}$ at $298 \mathrm{~K}$.

S9 $\quad{ }^{1} \mathrm{H}$ and ${ }^{13} \mathrm{C}$ NMR spectra of compound $7 \mathbf{a}$ in $\mathrm{CDCl}_{3}$ at $298 \mathrm{~K}$.

S10 $\quad{ }^{1} \mathrm{H}$ and ${ }^{13} \mathrm{C}$ NMR spectra of compound $\mathbf{8 c}$ in $\mathrm{CDCl}_{3}$ at $298 \mathrm{~K}$.

S11 Figure S1 with compared ${ }^{1} \mathrm{H}$ NMR spectra of compounds $7 \mathbf{c}, \mathbf{7 p}$ and $7 \mathbf{a}$.

S12 Figure S2 with high temperature ${ }^{1} \mathrm{H}$ NMR spectra of compound $\mathbf{5}$.

S13 Figure S3 with solvent and complexation effects on the conformational equilibrium in 5.

S14-S16 Typical complexation experiment, ${ }^{1} \mathrm{H}$ NMR spectra and treatment of the data

S17-S18 Crystallographic data collection and structure determinations. 


\section{General Methods}

NMR spectra were recorded on a $300 \mathrm{MHz}$ spectrometer, using halogenated solvents $\left(\mathrm{CDCl}_{3}\right.$ if not otherwise indicated) stored on activated $4 \AA$ molecular sieves with TMS as an internal standard. Mass spectra (ES-MS) were performed by an Electrospray Ionisation Time of Flight spectrometer. Melting points (uncorrected) were obtained in sealed evacuated capillaries. Column chromatography was carried out on 230-400 mesh silica gel. HPLC analyses were performed on a liquid chromatograph fitted with a UV/VIS detector operating at $230 \mathrm{~nm}$. Samples were analyzed on a LC-18 DB column $(25 \mathrm{~cm} \times 4.6 \mathrm{~mm}$ I.D., particle size $5 \mu \mathrm{m}$ ) using $\mathrm{MeOH}$ as the mobile phase. 


\section{7,13,21,27-Tetra-tert-butyl-29,30,31,32-tetrakis(methoxycarbonyl)methoxy-2,3,16,17-tetrahomo-}

3,17-dioxacalix[4]arene (5). A mixture of 2 (708 mg, $1.00 \mathrm{mmol})$, anhydrous $\mathrm{K}_{2} \mathrm{CO}_{3}(734 \mathrm{mg}, 5.32$ mmol), methyl bromoacetate $(7.72 \mathrm{~g}, 5.04 \mathrm{mmol})$ in dry acetone $(25 \mathrm{~mL})$ was stirred and refluxed during 6 days. After the usual work-up, recrystallization of the crude from $\mathrm{CHCl}_{3}-\mathrm{MeOH}$ yielded 6 (660 mg, 66\%). Recrystallization from several different solvents left the NMR spectra unchanged.

\section{7,13,21,27-Tetra-tert-butyl-29,30,31,32-tetrakis(ethoxycarbonyl)methoxy-2,3,16,17-tetrahomo-}

3,17-dioxacalix[4]arene (6). Prepared according to the literature, ${ }^{1}$ in $74 \%$ yield. Recrystallization from several different solvents left unchanged the NMR spectra.

\section{7,13,21,27-Tetra-tert-butyl-29,30,31,32-tetrakis(isopropoxycarbonyl)methoxy-2,3,16,17-}

tetrahomo-3,17-dioxacalix[4]arene, partial cone conformation (7p). A mixture of 2 (708 mg, 1.00 mmol), powdered $\mathrm{Me}_{4} \mathrm{NOH} \cdot 5 \mathrm{H}_{2} \mathrm{O}(1.18 \mathrm{~g}, 6.52 \mathrm{mmol})$, isopropyl bromoacetate (975 $\left.\mathrm{mg}, 5.39 \mathrm{mmol}\right)$ in dioxane $(25 \mathrm{~mL})$ was stirred and refluxed during 3 days under a nitrogen atmosphere. After the usual work-up, column chromatography $\left(\mathrm{SiO}_{2}\right.$, eluent: toluene-acetone 9:1) of the crude afforded 7a (21 mg, 2\%), 7c (80 mg, 7\%), and 7p (223 mg, 20\%).

\section{7,13,21,27-Tetra-tert-butyl-29,30,31,32-tetrakis(tert-butoxycarbonyl)methoxy-2,3,16,17-tetrahomo-} 3,17-dioxacalix[4]arene, cone conformation (8c). A mixture of 2 (500 $\mathrm{mg}, 0.71 \mathrm{mmol}$ ), anhydrous $\mathrm{K}_{2} \mathrm{CO}_{3}(516 \mathrm{mg}, 3.74 \mathrm{mmol})$, tert-butyl bromoacetate $(688 \mathrm{mg}, 3.53 \mathrm{mmol})$ in dry acetone $(18 \mathrm{~mL})$ was stirred and refluxed during 6 days. After the usual work-up, recrystallization of the crude from acetone yielded 8c (396 mg, 48\%), mp 203-204 ${ }^{\circ} \mathrm{C}$.

(1) Arnaud - Neu, F.; Cremin, S.; Cunningam, D.; Harris, S. J.; McArdle, P.; McManus, M. A.; Schwing - Weil, M. J.; Ziat, K. J. Inclusion Phenom. 1991, 10, 329. 

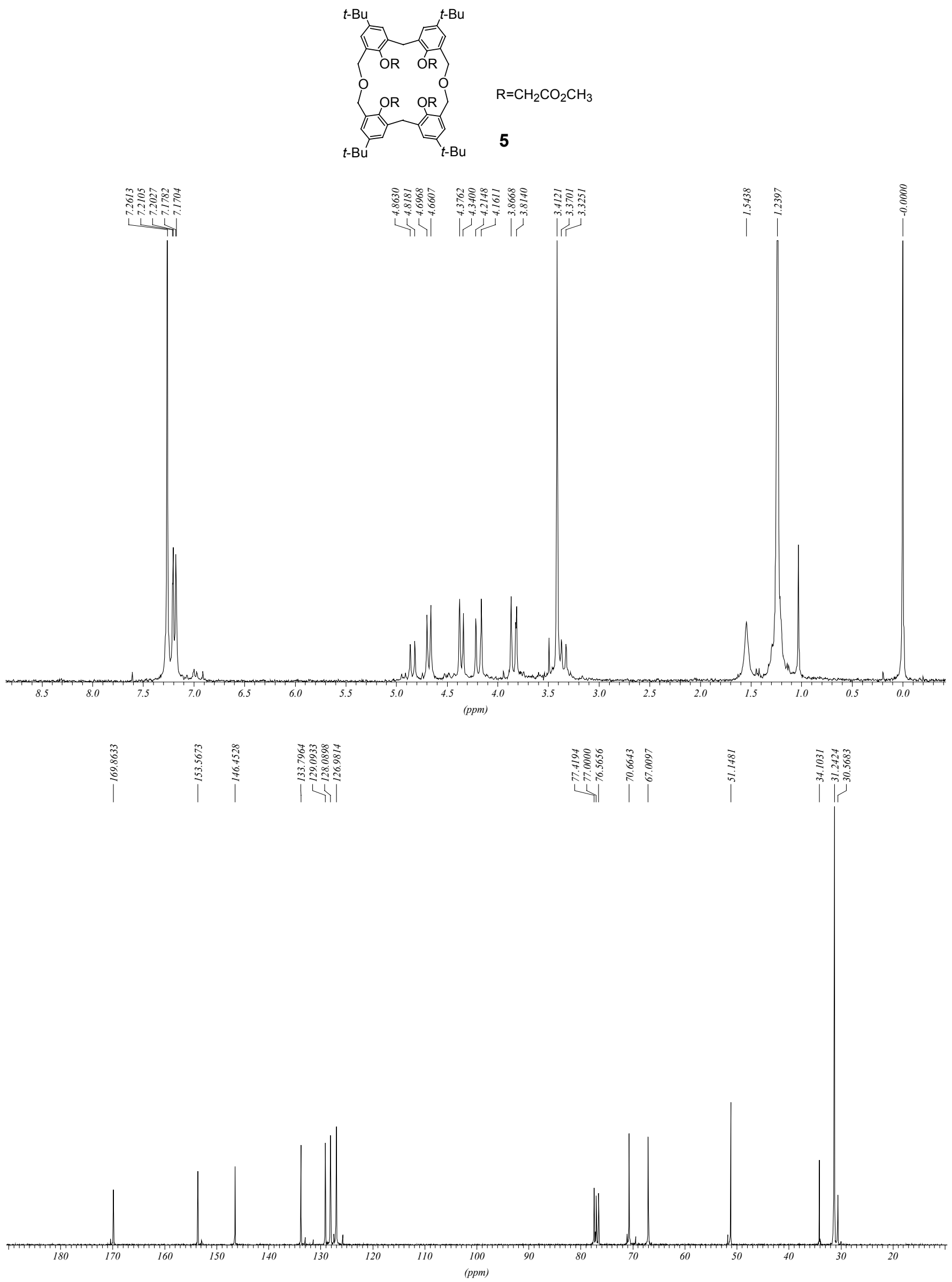


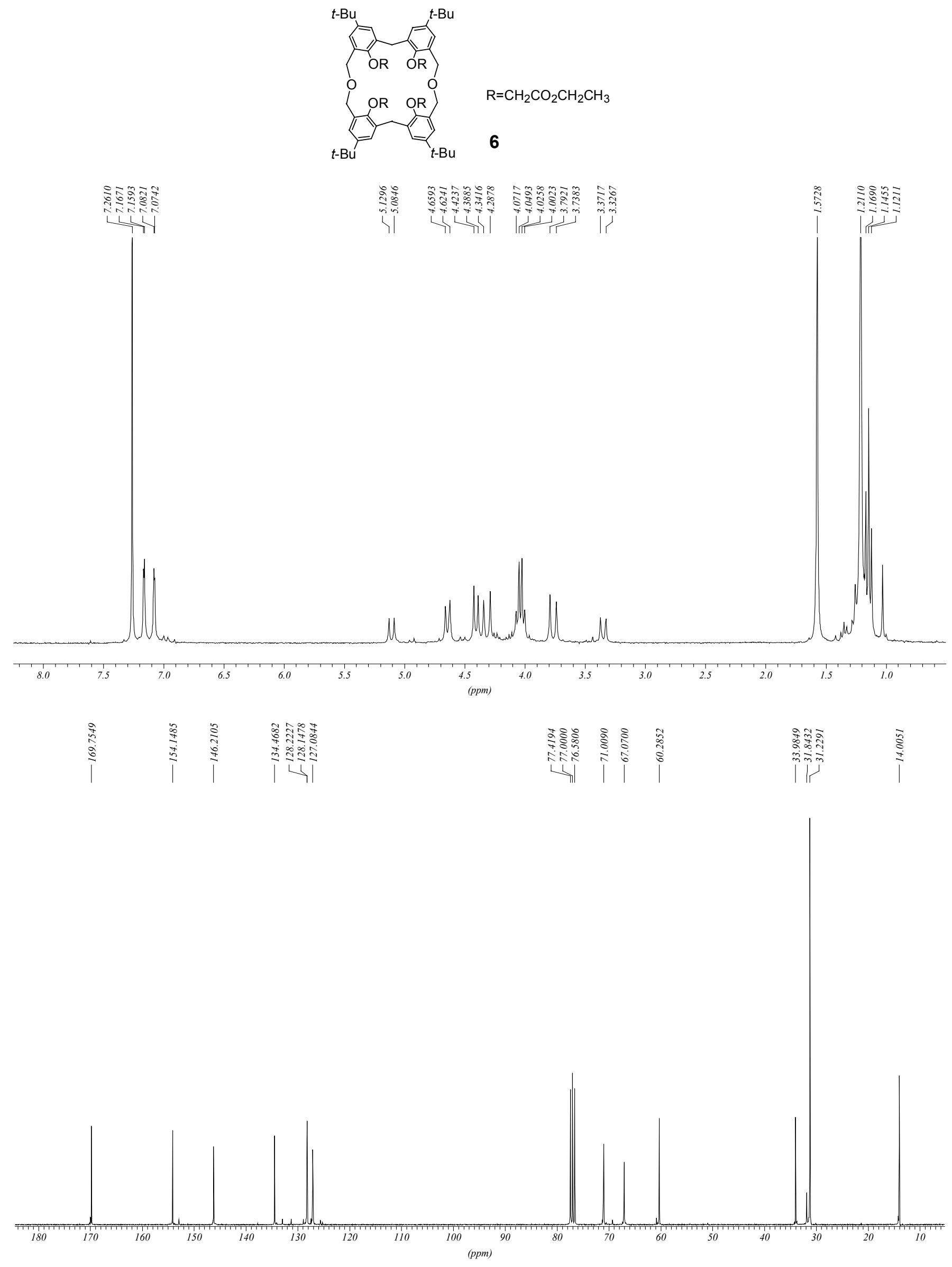



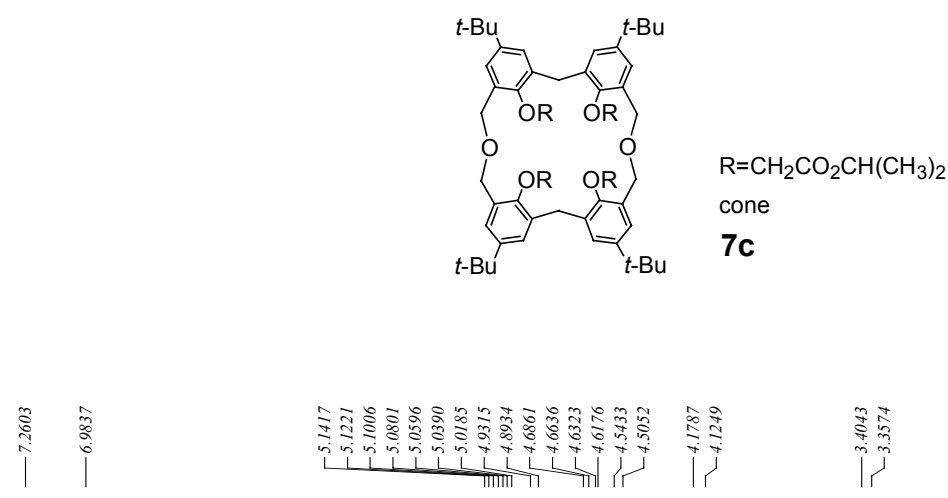

i

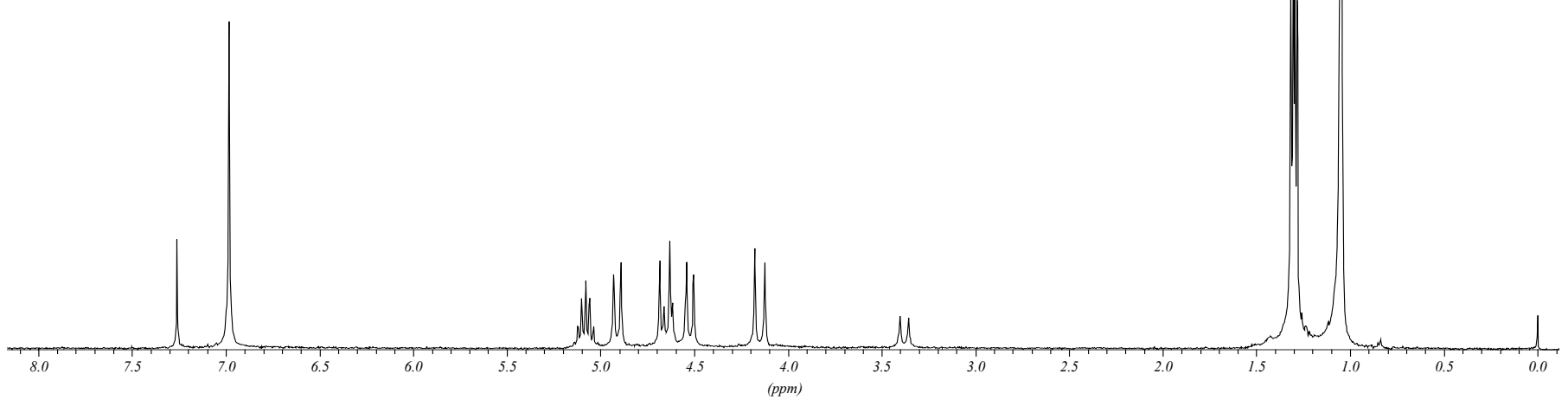

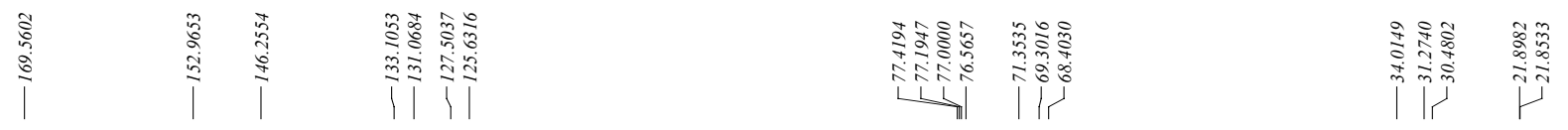

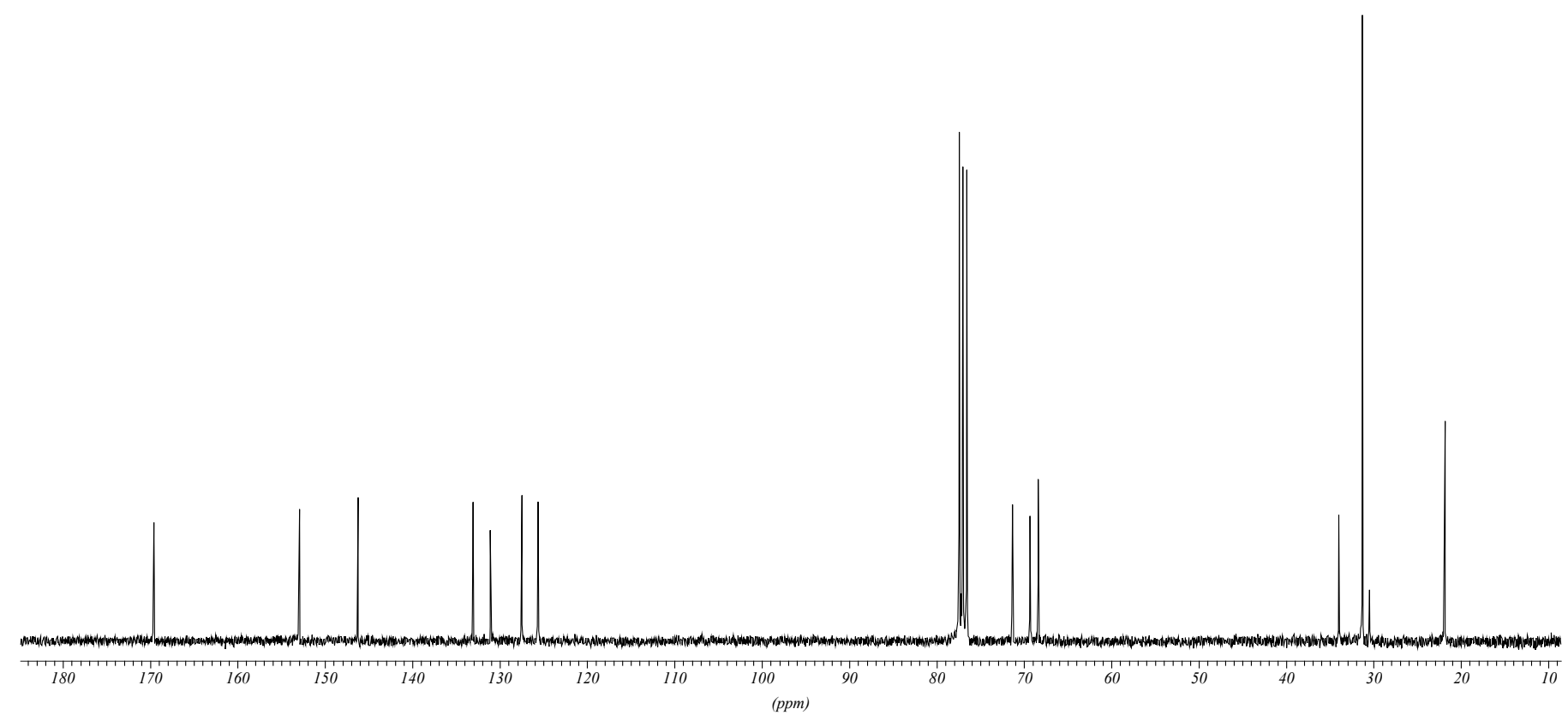



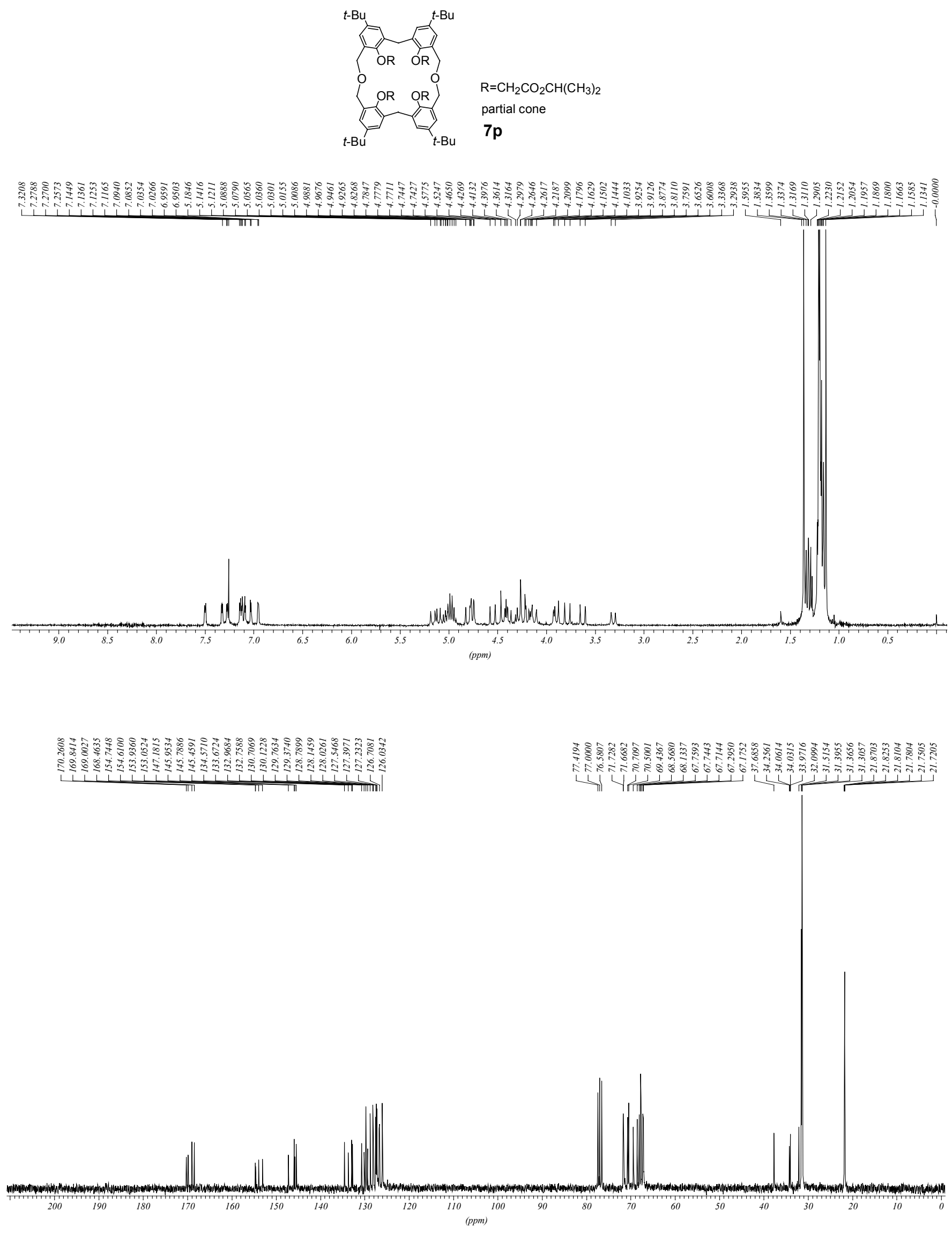


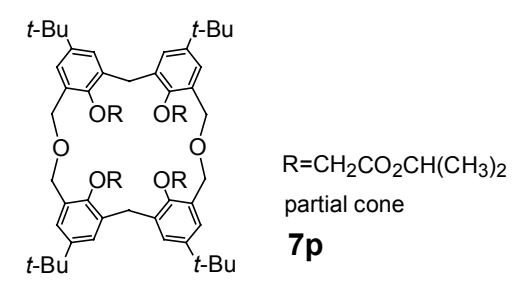

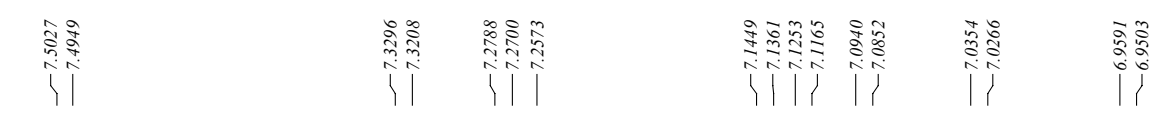
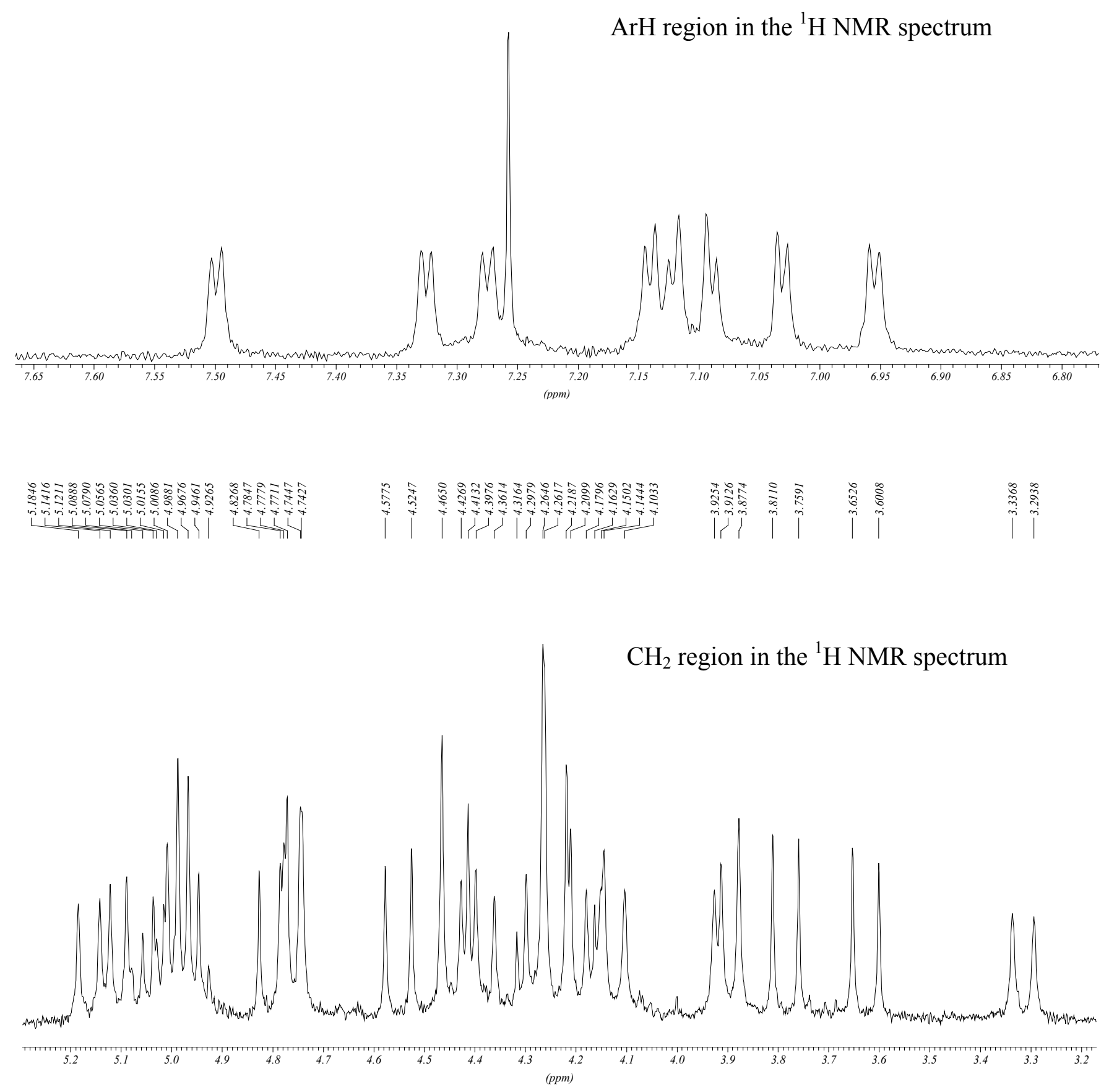


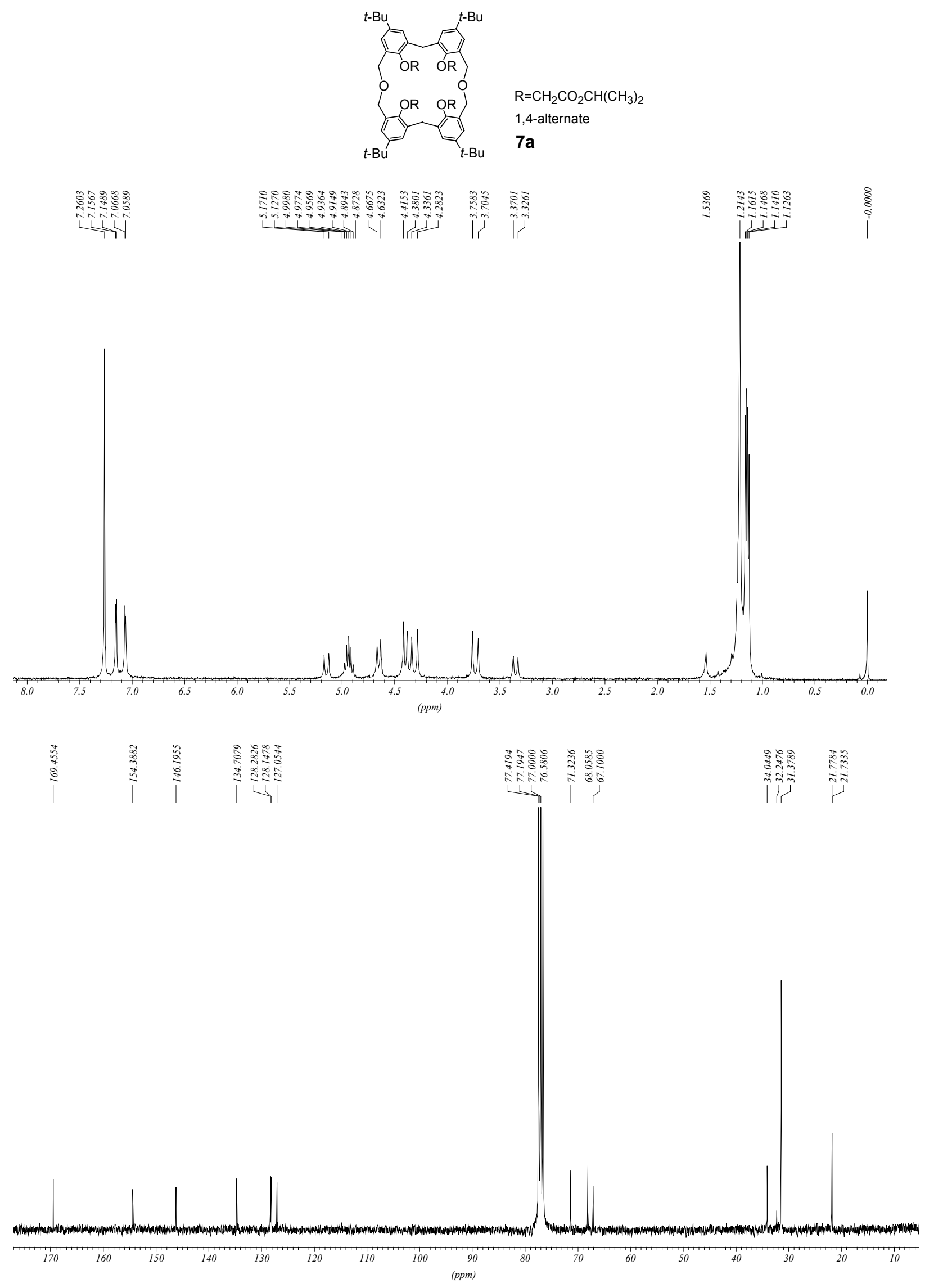



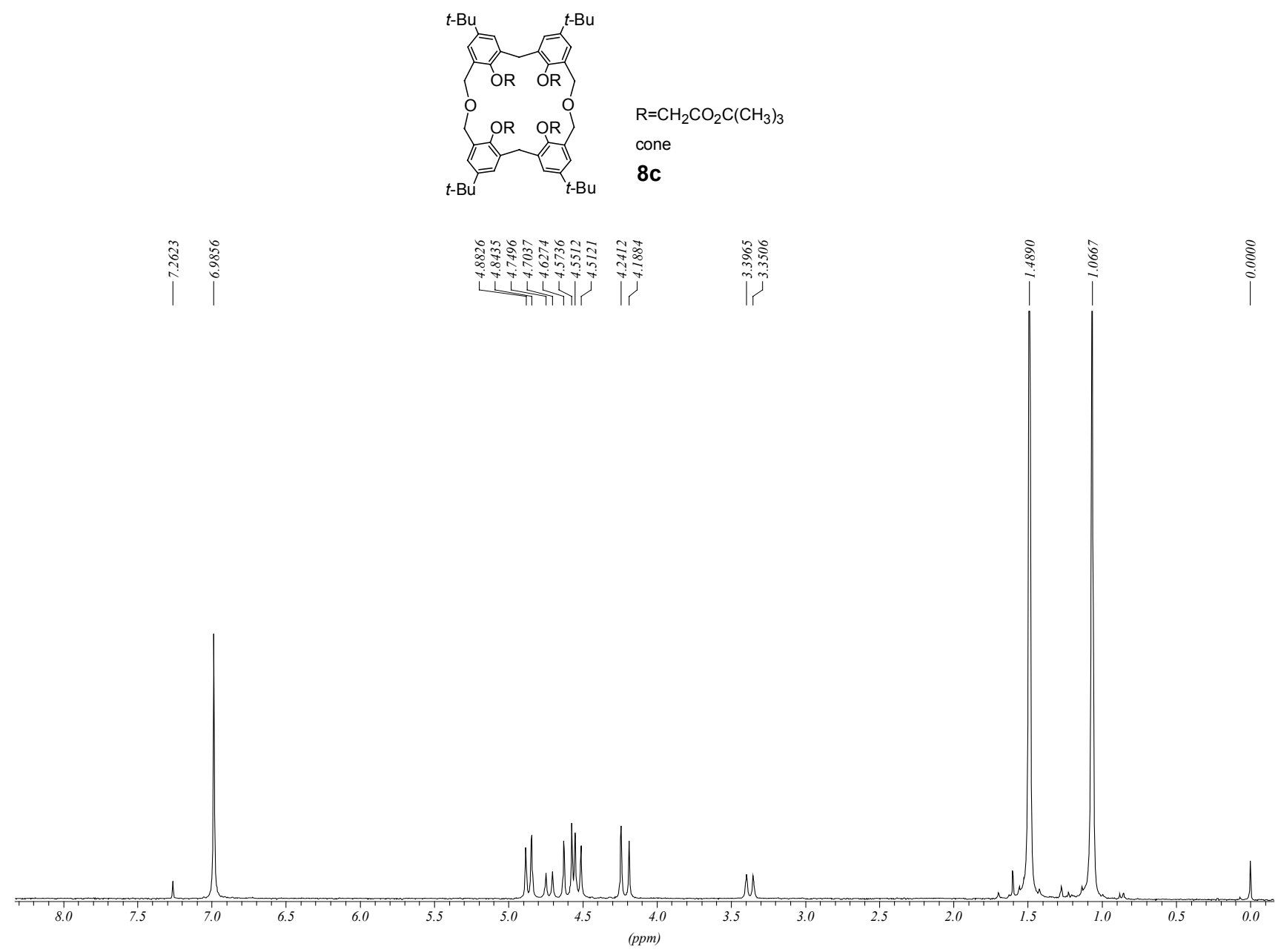

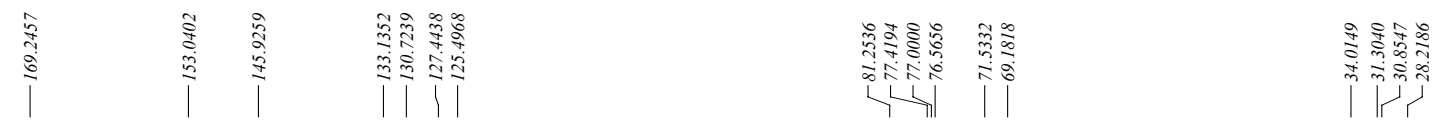

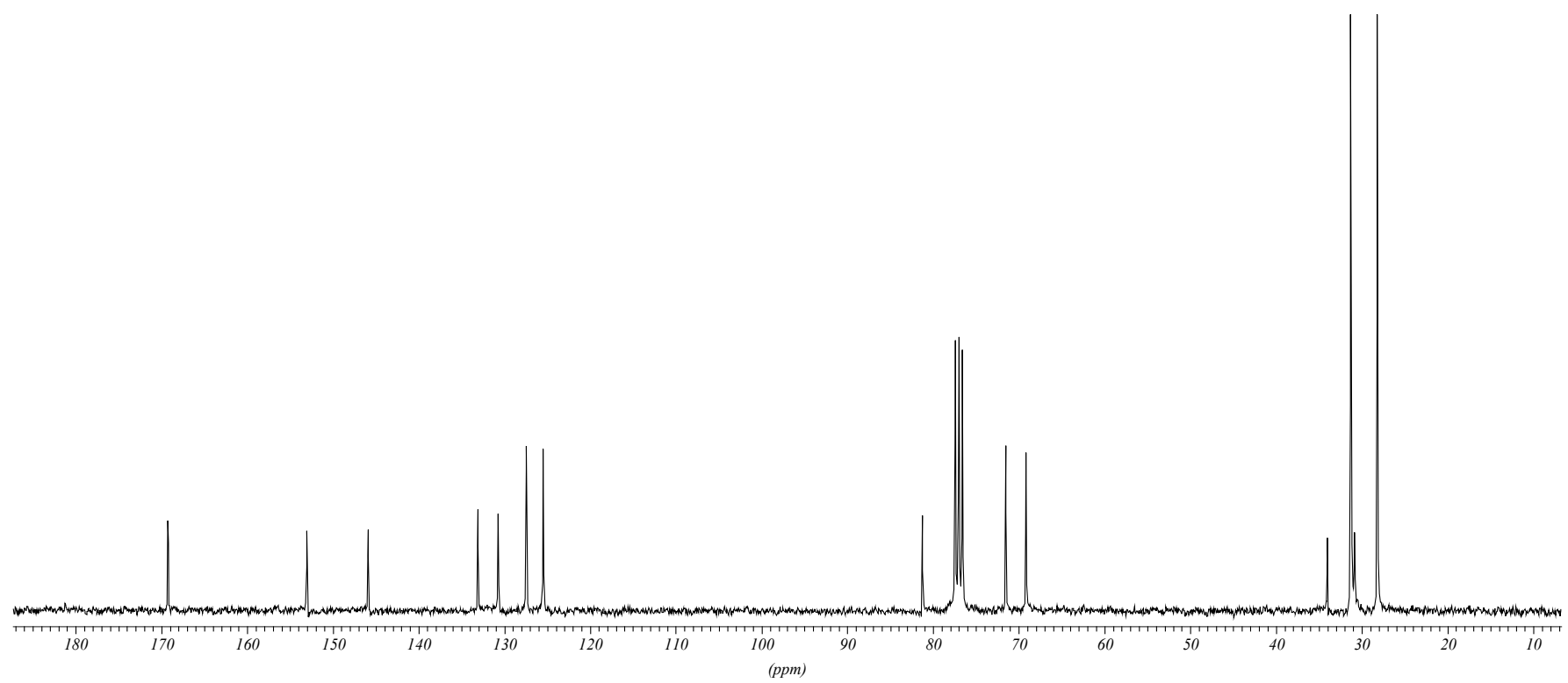



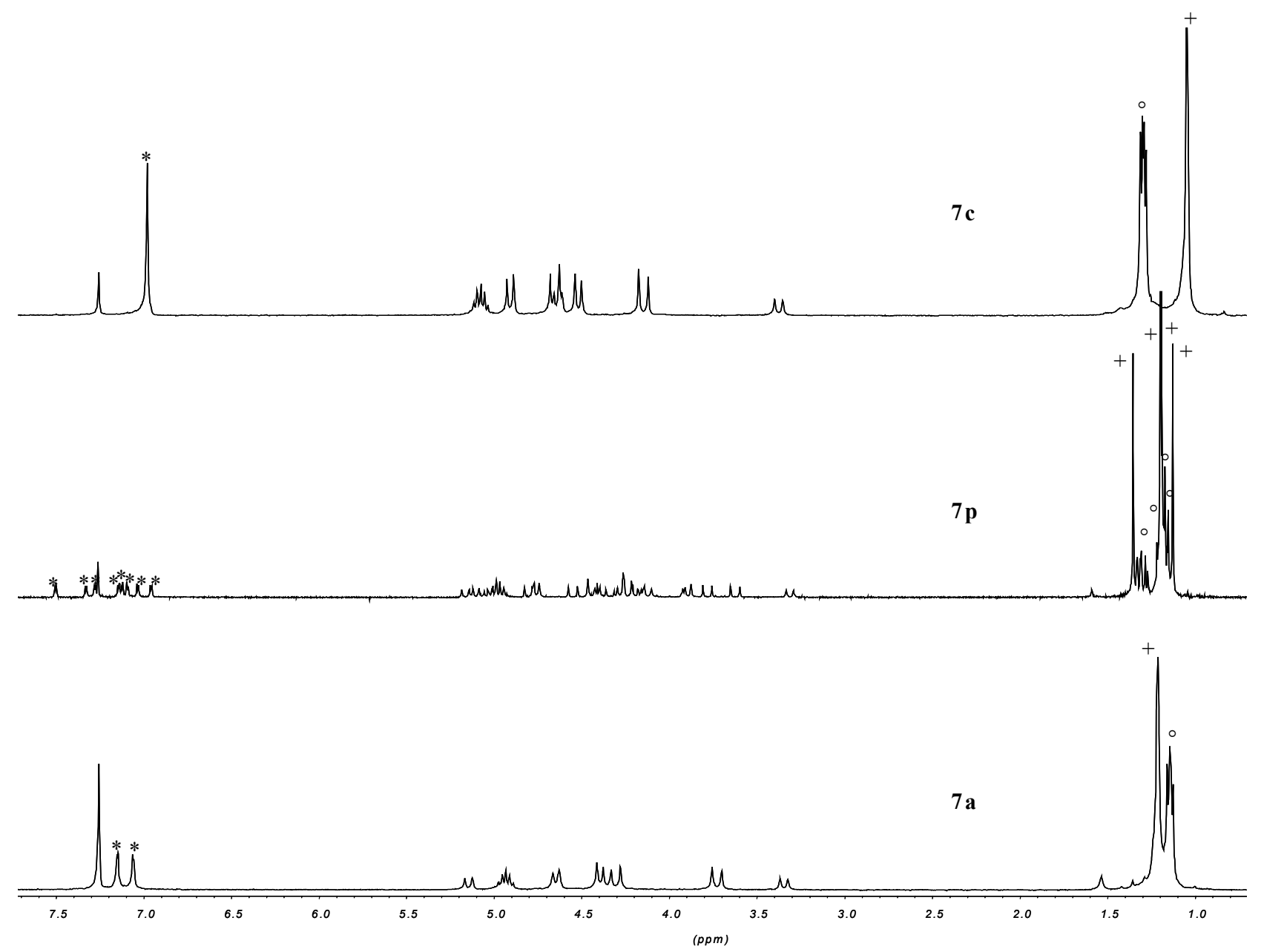

FigURE S1. ${ }^{1} \mathrm{H}$ NMR spectra of the three investigated stereoisomers 7c, 7p and 7a, in $\mathrm{CDCl}_{3}$ at $298 \mathrm{~K}$. Symbols ${ }^{*},+$, and ${ }^{\circ}$, mark $\mathrm{ArH}, \mathrm{C}\left(\mathrm{CH}_{3}\right)_{3}$ and $\mathrm{CH}\left(\mathrm{CH}_{3}\right)_{2}$ protons, respectively. 


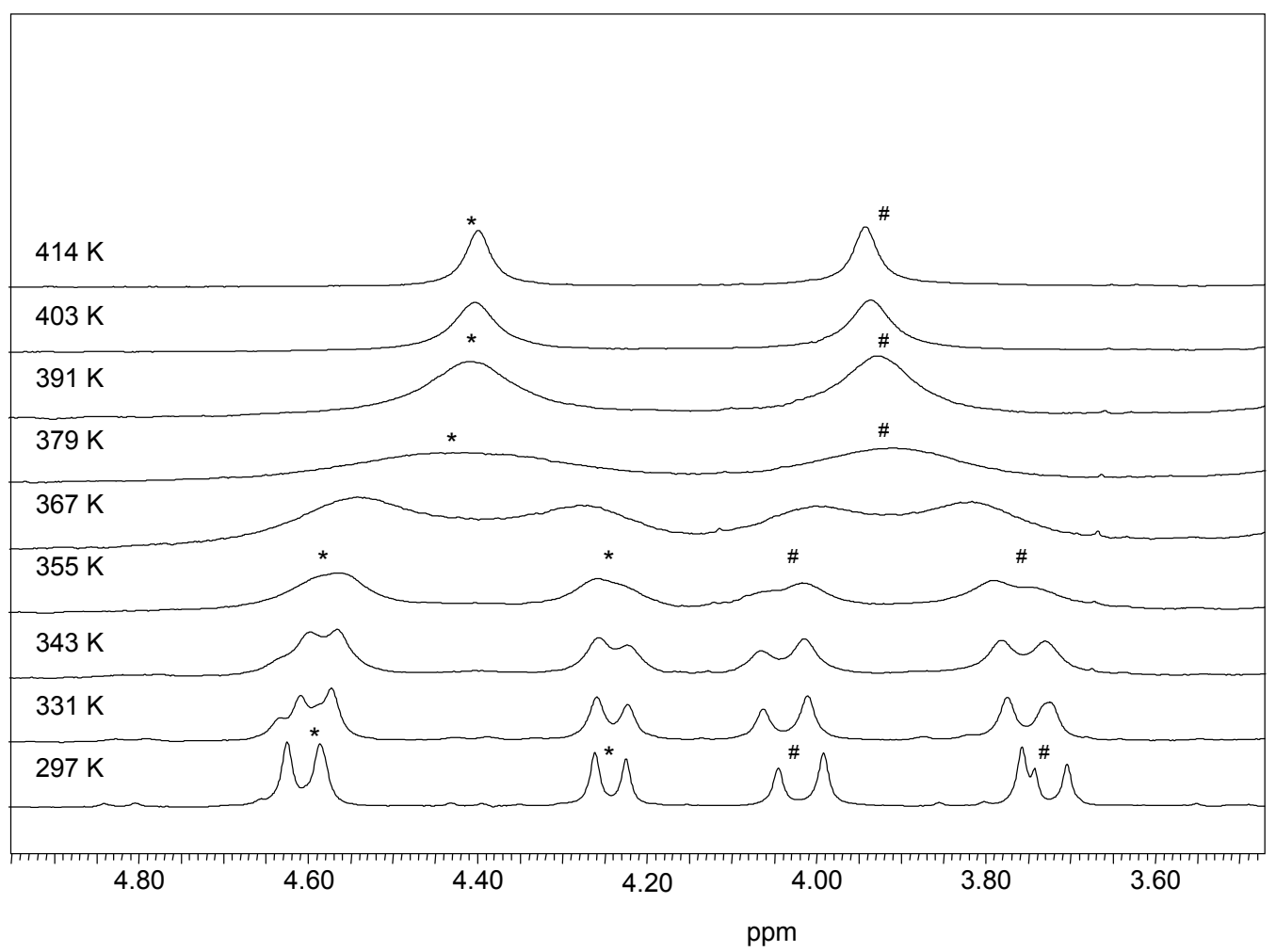

FIGURE S2. ${ }^{1} \mathrm{H}$ NMR spectra (central region) of compound 5 at high temperatures, in $\mathrm{CDCl}_{2} \mathrm{CDCl}_{2}$. Symbols mark the proposed splitting pattern for the 2 types of $\mathrm{OCH}_{2}$ protons. The signals of the $\mathrm{ArCH}_{2} \mathrm{Ar}$ protons are overlapped. 

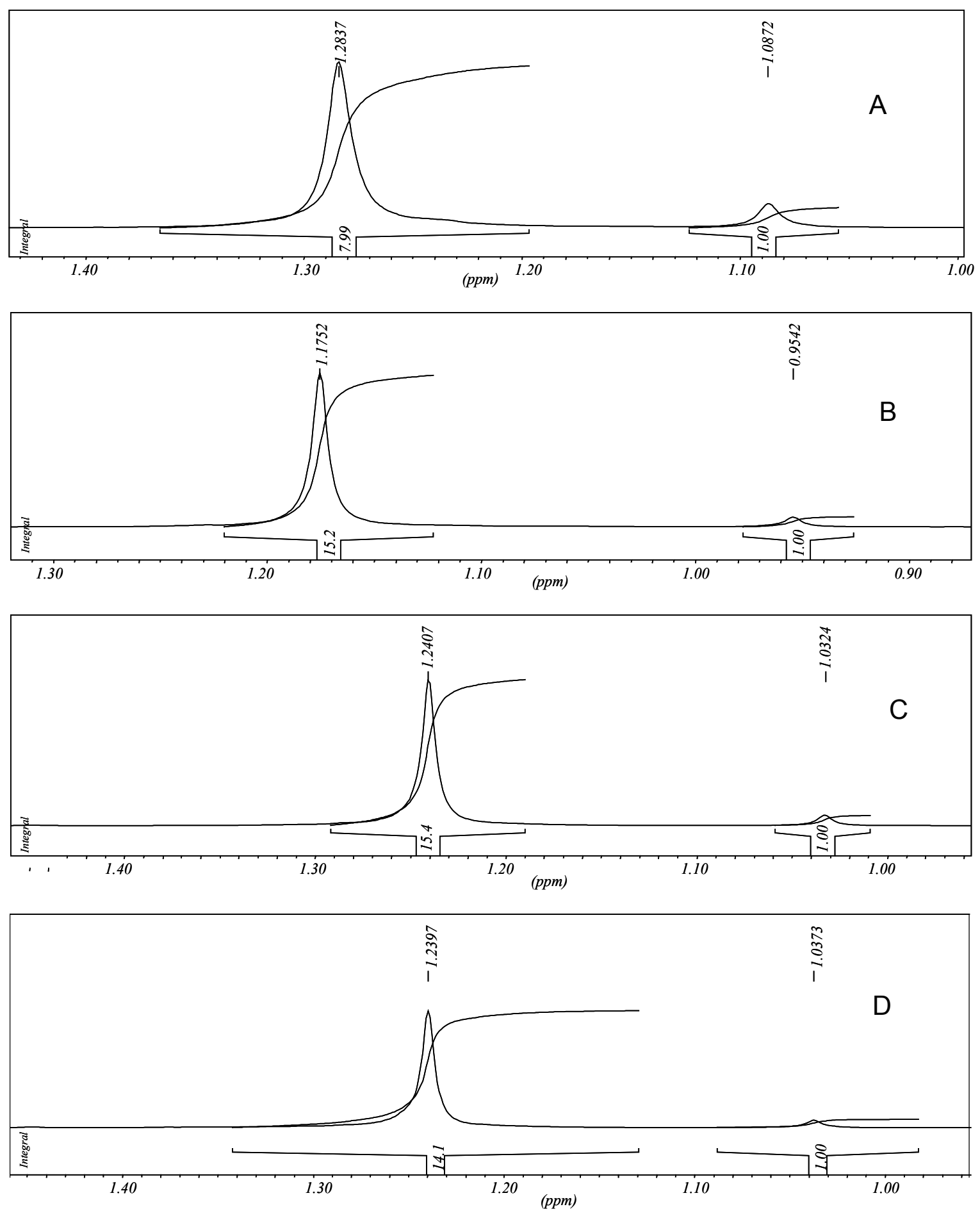

FIGURE S3. Solvent and complexation effect on the [1,4-alternate] / [cone] conformation ratio in compound 5 at $298 \mathrm{~K}$. Signals of the $t$-Bu protons in the ${ }^{1} \mathrm{H}$ NMR spectra (cone conformation at upper fields) in $\left(\mathrm{CD}_{3}\right)_{2} \mathrm{CO}(\mathrm{A})$, in $\mathrm{CDCl}_{2} \mathrm{CDCl}_{2}(\mathrm{~B})$, in $\mathrm{CDCl}_{3}(\mathrm{C})$ and in $\mathrm{CDCl}_{3}$ in the presence of excess solid tetramethylammonium picrate (D). 
Typical complexation experiment. ${ }^{1} \mathrm{H}$ NMR spectra for a typical complexation experiment are reported in Figure S4.

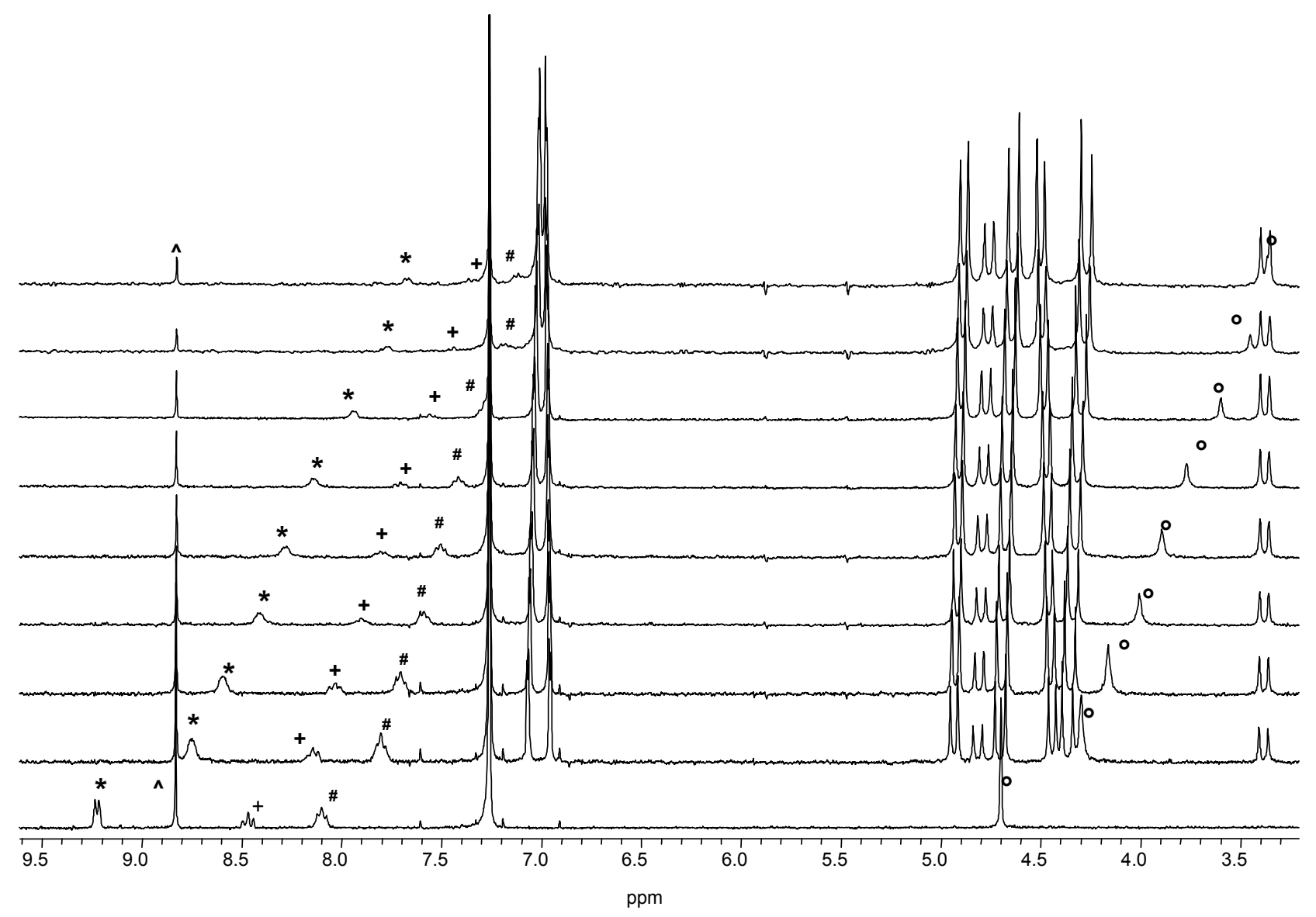

FIGURE S4. ${ }^{1} \mathrm{H}$ NMR spectra in $\mathrm{CDCl}_{3}$ at $298 \mathrm{~K}$ for titration of $1.00 \mathrm{mmol} \mathrm{L}^{-1} \mathrm{~N}$-methylpyridinium picrate with ligand $\mathbf{8 c}$, from bottom (no ligand added) to top (7.49 $\mathrm{mmol} \mathrm{L}^{-1}$ ligand). Marks *, +, \#, ^, 。 indicate $\alpha, \gamma, \beta$, picrate and $\mathrm{CH}_{3}$ protons, respectively. 
On assuming 1:1 association and fast equilibration, the standard eq S1 can be derived, with $c_{\mathrm{S}}=$ total salt concentration, $c_{\mathrm{L}}=$ total ligand concentration, $\delta_{0}=$ chemical shift in the absence of ligands, $\delta=$ chemical shift at a given ligand concentration, $\delta_{\infty}=$ limiting chemical shift for fully complexed salt, $K=$ association constant, and $D=\delta_{0}-\delta_{\infty}$

$$
\delta=\delta_{0}-\frac{D}{c_{S}} \frac{K^{-1}+c_{L}+c_{S}-\left\{\left(K^{-1}+c_{L}+c_{S}\right)^{2}-4 c_{L} c_{S}\right\}^{1 / 2}}{2}
$$

Least squares treatment of experimental data indicate that eq S1 is strictly obeyed, and afford optimized $D$ and $K$ values (Table $\mathrm{S} 1$ ). In Figure $\mathrm{S} 5$ the experimental points are plotted, along with the curves calculated from eq S1 using the optimized parameters.

TABLE S1. Results of the Multiparameter Least-Squares Treatment of the Data for Complexation of NMPP by $8 c^{a}$

$\begin{array}{lllll}\text { Parameter } & \text { Value } & \text { StdErr } & \text { CV }(\%) & \text { Dependencies } \\ D_{\mathrm{Me}} & 1.690 & 7 \cdot 10^{-3} & 4 \cdot 10^{-1} & 0.7061 \\ D_{\alpha} & 1.973 & 8 \cdot 10^{-3} & 4 \cdot 10^{-1} & 0.7661 \\ D_{\gamma} & 1.394 & 6 \cdot 10^{-3} & 4 \cdot 10^{-1} & 0.6204 \\ D_{\beta} & 1.253 & 6 \cdot 10^{-3} & 4 \cdot 10^{-1} & 0.5651 \\ K & 556.9 & 5.7 & 1.0 & 0.8960\end{array}$

${ }^{a}$ Data of the experiment reported in Figure S4. 


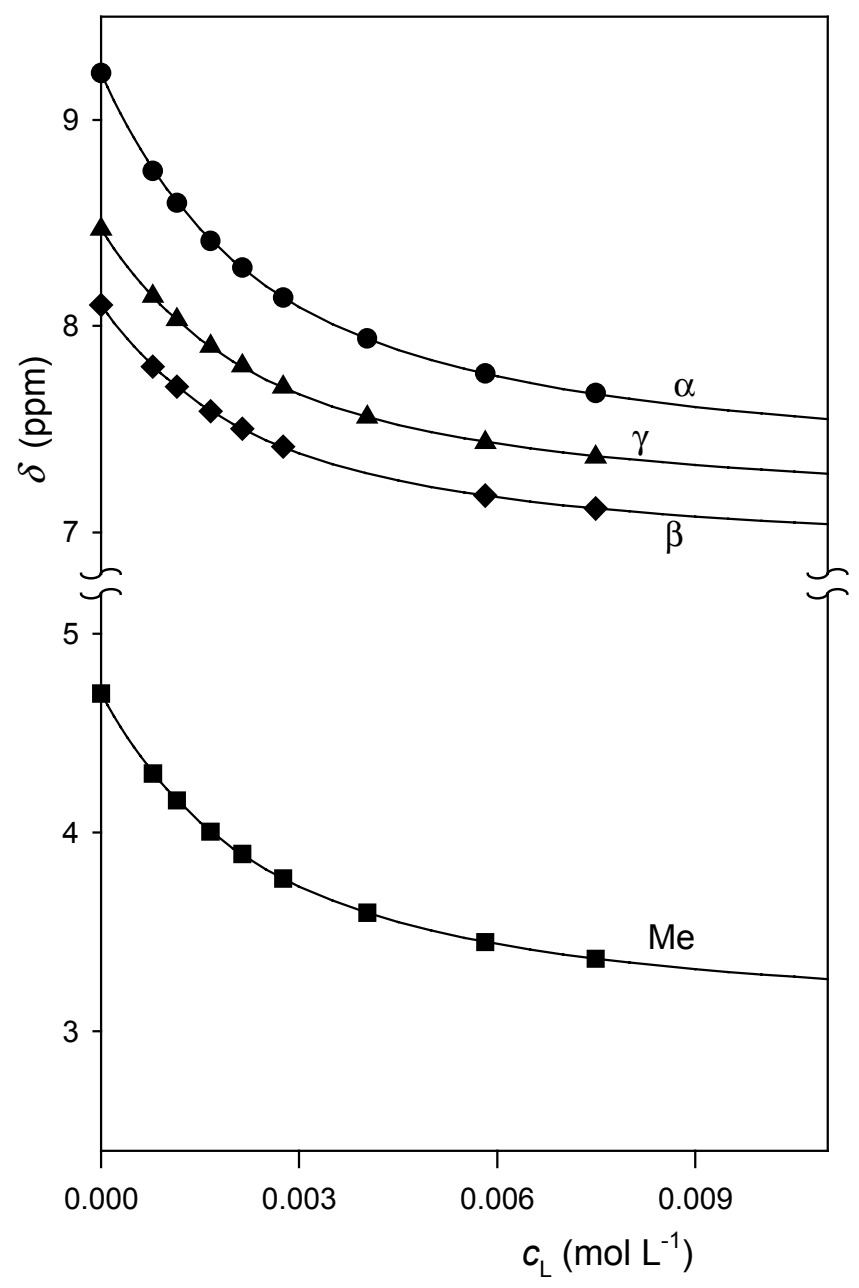

FIGURE S5. Titration of $N$-methylpyridinium picrate with ligand 8c: plots of $\delta$ values $v s$. total ligand concentration. The points are experimental (Figure S4) and the curves are calculated from the optimized parameters (Table S1). 
Crystallographic Data Collection and Structure Determinations. The data were collected at 100(2)

$\mathrm{K}$ on a Nonius Kappa-CCD area detector diffractometer ${ }^{1}$ using graphite-monochromated Mo-K $\alpha$ radiation $(\lambda=0.71073 \AA)$. The crystals were introduced in glass capillaries with a protecting "ParatoneN" oil (Hampton Research) coating. The unit cell parameters were determined from ten frames, then refined on all data. The data ( $\varphi$ - and $\omega$-scans) were processed with $H K L 2000 .^{2}$ The structures were solved by direct methods with SHELXS-97 and subsequent Fourier-difference synthesis and refined by blocked-matrix $\left(7 \mathbf{c} \cdot\left(\mathrm{CH}_{3}\right)_{2} \mathrm{CO}\right)$ or full-matrix $\left(\mathbf{8 c} \cdot\left(\mathrm{CH}_{3}\right)_{2} \mathrm{CO}\right)$ least-squares on $F^{2}$ with SHELXL-97. ${ }^{3}$ No absorption correction was applied. All non-hydrogen atoms were refined with anisotropic displacement parameters. Some restraints on bond lengths and/or displacement parameters were applied for two atoms of tert-butyl groups and the atoms of one of the solvent molecules in $7 \mathbf{c} \cdot\left(\mathrm{CH}_{3}\right)_{2} \mathrm{CO}$ and for the atoms of the badly resolved acetone molecule in $\mathbf{8 c} \cdot\left(\mathrm{CH}_{3}\right)_{2} \mathrm{CO}$. Hydrogen atoms were introduced at calculated positions and were treated as riding atoms with an isotropic displacement parameter equal to $1.2(\mathrm{CH}$, $\left.\mathrm{CH}_{2}\right)$ or $1.5\left(\mathrm{CH}_{3}\right)$ times that of the parent atom. Crystal data and structure refinement details are given in Table S1. The molecular plots were drawn with SHELXTL. ${ }^{4}$

(1) Kappa-CCD Software; Nonius B.V.: Delft, The Netherlands, 1998.

(2) Otwinowski, Z.; Minor, W. Methods Enzymol. 1997, 276, 307.

(3) Sheldrick, G. M. SHELXS-97 and SHELXL-97; University of Göttingen, Germany, 1997.

(4) Sheldrick, G. M. SHELXTL, Version 5.1; Bruker AXS Inc.: Madison, WI, USA, 1999. 
TABLE S2. Crystal Data and Structure Refinement Details

\begin{tabular}{|c|c|c|}
\hline & $7 \mathbf{c} \cdot\left(\mathrm{CH}_{3}\right)_{2} \mathrm{CO}$ & $\mathbf{8 c} \cdot\left(\mathrm{CH}_{3}\right)_{2} \mathrm{CO}$ \\
\hline empirical formula & $\mathrm{C}_{69} \mathrm{H}_{98} \mathrm{O}_{15}$ & $\mathrm{C}_{73} \mathrm{H}_{106} \mathrm{O}_{15}$ \\
\hline$M / \mathrm{g} \mathrm{mol}^{-1}$ & 1167.47 & 1223.58 \\
\hline crystal system & triclinic & triclinic \\
\hline space group & $P \overline{1}$ & $P \overline{1}$ \\
\hline$a / \AA$ & $18.1909(9)$ & $13.7593(8)$ \\
\hline$b / \AA$ & $19.4186(16)$ & $13.9522(11)$ \\
\hline$c / \AA$ & $22.3881(16)$ & $20.5857(16)$ \\
\hline$\alpha /^{\circ}$ & $100.282(4)$ & $83.983(3)$ \\
\hline$\beta /{ }^{\circ}$ & $111.204(4)$ & $89.968(4)$ \\
\hline$\gamma^{\circ}$ & $108.068(4)$ & $63.167(4)$ \\
\hline$V / \AA^{3}$ & $6621.8(9)$ & $3502.1(5)$ \\
\hline$Z$ & 4 & 2 \\
\hline$D_{\text {calc }} / \mathrm{g} \mathrm{cm}^{-3}$ & 1.171 & 1.160 \\
\hline$\mu(\mathrm{MoK} \alpha) / \mathrm{mm}^{-1}$ & 0.081 & 0.080 \\
\hline$F(000)$ & 2528 & 1328 \\
\hline reflections collected & 185869 & 25083 \\
\hline independent reflections & 25062 & 11951 \\
\hline observed reflections $[I>2 \sigma(I)]$ & 13196 & 7393 \\
\hline$R_{\text {int }}$ & 0.090 & 0.082 \\
\hline parameters refined & 1557 & 819 \\
\hline$R 1$ & 0.080 & 0.082 \\
\hline$w R 2$ & 0.233 & 0.227 \\
\hline$S$ & 1.004 & 1.000 \\
\hline$\Delta \rho_{\min } / \mathrm{e} \AA^{-3}$ & -0.54 & -0.54 \\
\hline$\Delta \rho_{\max } / \mathrm{e} \AA^{-3}$ & 0.74 & 1.12 \\
\hline
\end{tabular}

